\title{
Physical properties of biopolymers containing natamycin and rosemary extract
}

\author{
Hasan Türe, ${ }^{1}$ Erdal Eroğlu, ${ }^{1}$ Banu Özen ${ }^{2} * \&$ Ferda Soyer $^{3}$ \\ 1 Biotechnology and Bioengineering Programme, İzmir Institute of Technology, Urla-İzmir, Turkey \\ 2 Department of Food Engineering, İzmir Institute of Technology, Urla-İzmir, Turkey \\ 3 Department of Molecular Biology and Genetics, İzmir Institute of Technology, Urla-İzmir, Turkey
}

(Received 19 February 2008; Accepted in revised form 1 May 2008)

Summary Antifungal biopolymers were prepared by incorporating natamycin (NA) and NA + rosemary extract (RE) into wheat gluten (WG) and methyl cellulose (MC) films. Interaction between antimicrobial agents and biopolymers was determined with mid-infrared spectroscopy and scanning electron microscopy (SEM). Water vapour permeability and mechanical properties of these films were also measured. Mid-infrared spectroscopy did not indicate any interaction. SEM observations showed that NA crystallises at high concentrations in biopolymers. There were no significant changes in water vapour permeabilities of biopolymers containing active agents at $P<0.05$. While NA incorporation did not result in any changes in mechanical properties of WG films a reduction in tensile strength was observed for $\mathrm{MC}$ films containing high concentration of NA. In general, active agent incorporation into WG and MC films did not result in any considerable changes in their physical properties that could affect their application.

Keywords Methyl cellulose film, natamycin, rosemary extract, wheat gluten film.

\section{Introduction}

Recent studies on food packaging especially focus on development of biopolymers that have additional functions such as antimicrobial and antioxidant properties besides traditional role of a packaging film. These types of packaging films could be effective in delaying or inhibiting microbial growth originating from post-processing contamination. Biopolymers could be prepared from renewable sources such as whey protein, corn protein zein, alginates and starch, and provide protection of food against moisture, gases and vapour. Various antimicrobial agents such as bacteriocins and plant extracts were incorporated alone or in combination into different types of biopolymers (Quattara et al., 2000; Cutter et al., 2001; Ozdemir \& Floros, 2003; Min et al., 2005). Combinations of antimicrobial agents might have enhanced antimicrobial effect compared with individual agents owing to their synergistic action. In our previous study, it was shown that wheat gluten (WG) and methyl cellulose (MC) films with natamycin (NA) have antifungal activities against Aspergillus niger and Penicillium roquefortii. Although rosemary extract

*Correspondent: Fax: 90232750 6196;

e-mail: banuozen@iyte.edu.tr
(RE) did not have any inhibitory effect against these two fungi it enhanced the inhibitory activity of NA in WG and MC films (Ture et al., 2007). Only NA containing casein coatings and cellulose-based films were used to prevent mould spoilage in cheese (Yildirim et al., 2006; de Oliveira et al., 2007).

Incorporation of antimicrobial and/or antioxidant agents into films adds new functionality to packaging. However, addition of these agents into the film may cause changes in the structure and the properties of the films. Modification in the structure could arise from interactions between added agent and the film. Mid-infrared spectroscopy and scanning electron microscopy (SEM) could be useful in determining these interactions (Pranoto et al., 2005; Maizura et al., 2007). While some agents did not have any effect on the barrier and mechanical properties of the biopolymers, modifications were also reported in several studies depending on the nature of the antimicrobial agent and the biopolymer (Ko et al., 2001; Pranoto et al., 2005; Bifani et al., 2007).

The aims of this study are to determine the effect of NA, RE and combination of NA and RE incorporation on water vapour barrier and mechanical properties of WG and MC films, and also to evaluate the interaction between active agents and films by infrared spectroscopic and SEM analysis. 


\section{Materials and methods}

\section{Materials}

Pimalac ${ }^{\circledR}$ used as NA source was provided by Mayasan (Istanbul, Turkey). All reagents were of analytical grade and were purchased from Sigma (St. Louis, MO, USA).

\section{Rosemary extraction}

Rosemary leaves were collected from Urla region of Turkey and extraction was performed immediately. RE was produced using a modified procedure of Madsen et al. (1998). Rosemary leaves (12 g) were homogenised in $70 \mathrm{~mL}$ of absolute ethanol at 26000 r.p.m. (Heidolph Silent Crusher M Homogenizer, Germany) for $5 \mathrm{~min}$. The solution obtained was stirred for $30 \mathrm{~min}$ in dark and cenrifugated at 5000 r.p.m. (Nüve NF 615, Turkey) for $5 \mathrm{~min}$. The supernatant was collected and $30 \mathrm{~mL}$ of ethanol was added to precipitate and the same procedure was repeated twice. In the last extraction step, $20 \mathrm{~mL}$ of ethanol was used. The collected supernatant was evaporated under vacuum at $40{ }^{\circ} \mathrm{C}$ for approximately $1 \mathrm{~h}$ with a rotary evaporator (Heidolph Laborata4000, Germany). The obtained extract was vacuum-filtered through $5 \mu \mathrm{m}$ cellulose nitrate filter. Approximately $25 \mathrm{~mL}$ of extract was obtained.

\section{Preparation of WG and MC films and incorporation of active agents}

WG films were prepared according to a method by Pochat-Bohatier et al. (2006) with some modifications. Fifteen grams of WG (Sigma-Aldrich, Germany) was dissolved in $31.5 \mathrm{~mL}$ of absolute ethanol with mixing. Then, $0.03 \mathrm{~g}$ of sodium sulphite, $3 \mathrm{~g}$ of glycerol and $63 \mathrm{~mL}$ of distilled water were added to the solution and mixed with a magnetic stirrer. The $\mathrm{pH}$ of the film solution was set to 4 with acetic acid and the solution was mixed and heated to $70{ }^{\circ} \mathrm{C}$ in a magnetic stirrer. Ten gram of film solution (fs) was spread onto $8.5-\mathrm{cm}$ diameter polystyrene petri dishes and dried at $30{ }^{\circ} \mathrm{C}$ overnight.

A procedure by Turhan \& Sahbaz (2004) with some modifications was used for the preparation of MC films. Three gram of MC (Sigma-Aldrich) was mixed with $50 \mathrm{~mL}$ of ethanol. Fifty millilitre of distilled water was added and homogenised. After addition of $1 \mathrm{~mL}$ glycerol, the solution was heated to $80^{\circ} \mathrm{C}$. Ten gram of fs was spread onto polystyrene petri dishes and dried at $30{ }^{\circ} \mathrm{C}$ overnight.

NA-containing films were prepared exactly like control films, but NA in powder form was added to films just before spreading fs onto petri dishes at a temperature of $50-55{ }^{\circ} \mathrm{C}$. After addition of NA, the fs was mixed for about 5 min with a magnetic stirrer.
Concentration of NA was in the range of $0.2-40 \mathrm{mg}$ per $10 \mathrm{~g}$ fs.

RE-containing films were produced by replacing a certain volume of ethanol and water in film formulation with RE $(2.3 \mathrm{~mL}$ alcohol and $0.7 \mathrm{~mL}$ water for $3 \mathrm{~mL}$ $\mathrm{RE}$ in $10 \mathrm{~g}$ fs). NA + RE-containing films were made according to procedures explained before and adding $\mathrm{RE}$ and NA before spreading fs onto plate. The average thickness of films (mm) was measured randomly at ten points with a hand micrometer (SHAN Electronic, China).

\section{Measurement of mechanical properties}

The films were conditioned at $50 \%$ relative humidity and at about $23{ }^{\circ} \mathrm{C}$ in desiccators for $48 \mathrm{~h}$ before the measurement of mechanical properties. Relative humidity was adjusted by placing saturated solution of magnesium nitrate inside desiccators. Tensile strength (TS), elastic modulus (EM) and elongation at break (EB) of films were tested according to ASTM Method D882 (1996) by using Mechanical Testing Machine (AG-I 250 kN, Schimadzu, Japan). Films were cut into $25 \mathrm{~mm} \times 100 \mathrm{~mm}$ strips. Two hundred and fifty Newton load cell was used for both films. Initial grip separation was $50 \mathrm{~mm}$ and head speed was set to $50 \mathrm{~mm} \mathrm{~min}^{-1}$. At least six replicates were performed in each case.

\section{Measurement of water vapour barrier properties}

The films were conditioned at $50 \%$ relative humidity and at about $23{ }^{\circ} \mathrm{C}$ in desiccators for at least $48 \mathrm{~h}$ before the measurement of water vapour permeability (WVP). WVP of films was measured according to WVP Correction Method (McHugh et al., 1993). Glass jars containing water were sealed with films and placed in desiccators containing saturated solutions of $\mathrm{MgNO}_{3}(50 \%$ relative humidity). The desiccators were kept in a room at $25{ }^{\circ} \mathrm{C}$. The area of jar mouth was $17.34 \mathrm{~cm}^{2}$, and the jar depth was $7 \mathrm{~cm}$. The gap between the film and water in the jar was $1.4 \mathrm{~cm}$. Fans operating at speeds of $2 \mathrm{~m} \mathrm{~s}^{-1}$ were also placed in the desiccators and the fan speed was measured with an anemometer (Turbo Meter, Hayward, CA, USA). Three replicates of each film were tested. The weight changes of glass jars were measured and plotted against time. WVP Correction Method (McHugh et al., 1993) was used in calculation of relative humidities of the films' undersides and WVP values.

\section{Fourier transform infrared spectroscopy measurement}

Infrared spectra of the films were obtained in 4000 $650 \mathrm{~cm}^{-1}$ range with a Perkin Elmer Spectrum 100 Fourier transform infrared spectrometer (Perkin Elmer Inc., Wellesley, MA, USA) equipped with a deuterated tri-glycine sulphate (DTGS) detector. A horizontal 
attenuated total reflectance (HATR) sampling accessory (ZnSe crystal) was used to collect the spectral data of the films. The resolution was set at $4 \mathrm{~cm}^{-1}$ and the number of scans collected for each spectrum was 64 .

\section{SEM analysis}

The films were conditioned at $50 \%$ relative humidity in a desiccator for at least $48 \mathrm{~h}$ before SEM analysis. The films were coated with 100-200 $\AA$ thickness of gold. Cross-section of films were scanned with XL-30S FEG electron microscope (Phillips, The Netherlands).

\section{Statistical analysis}

WVP and mechanical properties data were analysed by analysis of variance (ANOVA) using the MINITAB (version 14.10; State College, PA, USA). The means were compared using Fisher least significant difference (LSD) method at $P=0.05$.

\section{Results and discussion}

While MC film used in this study is carbohydrate-based and WG is prepared from one of the major protein fraction of wheat. NA and RE were added to these films to provide antimicrobial properties (Ture et al., 2007). NA is an amphoteric compound produced by Streptomyces natalensis. RE contains phenolic diterpenes such as carnosic acid, carnosol, rosmanol, epirosmanol, isorosmanol, methyl carnosate and other phenolic acids, such as rosmarinic acid (Schwarz \& Ternes, 1992; Cuvelier et al., 1996). The physical properties of films which were proved to have antifungal activities were investigated in this study.

Both WG and MC films were homogenous, thin and flexible. While films prepared from WG were opaque MC films were clear. Adding active agents to films did not have any effect on their visual appearance. The thicknesses of prepared films are presented in Table 1. There were no significant differences in thicknesses between control and NA or NA + RE-added films except MC containing $20 \mathrm{mg}$ NA per $10 \mathrm{~g}$ fs.

\section{Mechanical properties of films}

Mechanical properties of control and NA, NA + REcontaining WG and $\mathrm{MC}$ films are listed in Table 1. Incorporation of NA into WG film did not cause major changes in its mechanical properties. As antimicrobial synergy between NA and RE was observed at low NA concentration (Ture et al., 2007), mechanical properties of the films containing $0.5-2 \mathrm{mg}$ NA per $10 \mathrm{~g}$ fs in combination with RE were tested. A decrease in TS $(15.5 \%)$ and $\mathrm{EM}(50 \%)$ of WG films was observed at $2 \mathrm{mg}$ NA per $10 \mathrm{~g}$ fs $+1.5 \mathrm{~mL}$ RE per $10 \mathrm{~g}$ fs. In addition, the elongation increased with increasing NA concentration for WG films containing RE.

For MC films, TS decreased at 10 and $20 \mathrm{mg}$ NA per $10 \mathrm{~g}$ fs, and reduction in TS at the highest NA concentration corresponds to a value of $38.3 \%$ relative to the control. As it was observed in SEM pictures, high

Table 1 Mechanical and water vapour properties of wheat gluten (WG) and methyl cellulose (MC) films

\begin{tabular}{|c|c|c|c|c|c|c|c|}
\hline \multirow[b]{2}{*}{ Film } & \multirow[b]{2}{*}{$\begin{array}{l}\text { Natamycin } \\
\text { (mg per } 10 \mathrm{~g} \mathrm{fs} \text { ) }\end{array}$} & \multirow[b]{2}{*}{$\begin{array}{l}\text { Rosemary } \\
\text { extract } \\
\text { (mL per } 10 \mathrm{~g} \mathrm{fs} \text { ) }\end{array}$} & \multirow[b]{2}{*}{ Thickness (mm) } & \multicolumn{3}{|c|}{ Mechanical properties } & \multirow[b]{2}{*}{ 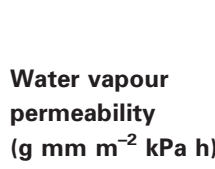 } \\
\hline & & & & $\begin{array}{l}\text { Tensile } \\
\text { strength (MPa) }\end{array}$ & $\begin{array}{l}\text { Elastic } \\
\text { modulus } \\
\left(\mathrm{N} \mathrm{mm}^{-2}\right)\end{array}$ & $\begin{array}{l}\% \text { elongation } \\
\text { at break }\end{array}$ & \\
\hline \multirow[t]{8}{*}{ WG } & 0 & 0 & $0.25 \pm 0.028^{a}$ & $2.06 \pm 0.27^{a}$ & $28.79 \pm 11.62^{a}$ & $224.80 \pm 53.01^{a}$ & $6.85 \pm 0.56^{a}$ \\
\hline & 2 & 0 & $0.22 \pm 0.036^{a}$ & $2.01 \pm 0.28^{a}$ & $28.21 \pm 9.26^{a}$ & $225.32 \pm 49.18^{a}$ & $5.99 \pm 2.23^{a}$ \\
\hline & 5 & 0 & $0.23 \pm 0.022^{\mathrm{a}}$ & $2.00 \pm 0.17^{a}$ & $23.29 \pm 3.93^{a}$ & $254.76 \pm 56.80^{a}$ & $6.36 \pm 0.67^{a}$ \\
\hline & 10 & 0 & $0.24 \pm 0.026^{a}$ & $2.10 \pm 0.19^{a}$ & $27.25 \pm 3.29^{a}$ & $227.87 \pm 41.00^{a}$ & $6.47 \pm 0.95^{\mathrm{a}}$ \\
\hline & 20 & 0 & $0.24 \pm 0.023^{a}$ & $2.23 \pm 0.11^{\mathrm{a}}$ & $29.62 \pm 5.18^{a}$ & $225.10 \pm 20.97^{a}$ & $6.42 \pm 0.65^{a}$ \\
\hline & 1 & 1.5 & $0.23 \pm 0.034^{a}$ & $2.02 \pm 0.21^{\mathrm{a}}$ & $20.62 \pm 3.44^{\mathrm{a}}$ & $260.92 \pm 11.00^{a}$ & $5.99 \pm 0.71^{\mathrm{a}}$ \\
\hline & 1.5 & 1.5 & $0.23 \pm 0.037^{a}$ & $2.20 \pm 0.09^{a}$ & $21.19 \pm 3.43^{\mathrm{a}}$ & $278.12 \pm 16.72^{a}$ & $6.04 \pm 0.74^{a}$ \\
\hline & 2 & 1.5 & $0.23 \pm 0.037^{a}$ & $1.74 \pm 0.13^{b}$ & $14.68 \pm 1.08^{b}$ & $295.95 \pm 15.42^{b}$ & $6.26 \pm 0.25^{\mathrm{a}}$ \\
\hline \multirow[t]{8}{*}{ MC } & 0 & 0 & $0.063 \pm 0.009^{a}$ & $36.63 \pm 7.53^{\mathrm{a}}$ & $313.23 \pm 56.89^{b c}$ & $73.98 \pm 13.22^{b}$ & $3.50 \pm 0.25^{a}$ \\
\hline & 2 & 0 & $0.069 \pm 0.01^{\mathrm{a}}$ & $37.17 \pm 11.95^{a}$ & $380.73 \pm 58.36^{a}$ & $60.45 \pm 17.67^{a}$ & $3.43 \pm 0.57^{a}$ \\
\hline & 5 & 0 & $0.066 \pm 0.01^{\mathrm{a}}$ & $33.80 \pm 6.11^{\mathrm{a}}$ & $346.03 \pm 51.79^{\mathrm{ac}}$ & $66.47 \pm 6.58^{\mathrm{ab}}$ & $3.20 \pm 0.25^{\mathrm{a}}$ \\
\hline & 10 & 0 & $0.065 \pm 0.01^{a}$ & $27.28 \pm 3.80^{b}$ & $263.87 \pm 31.97^{b}$ & $66.78 \pm 2.51^{a b}$ & $3.79 \pm 0.41^{a}$ \\
\hline & 20 & 0 & $0.075 \pm 0.005^{b}$ & $22.59 \pm 4.98^{b}$ & $299.90 \pm 27.21^{b c}$ & $56.76 \pm 9.18^{a}$ & $4.11 \pm 0.74^{a}$ \\
\hline & 1 & 1.5 & $0.064 \pm 0.009^{a}$ & $36.09 \pm 5.36^{a}$ & $426.75 \pm 35.47^{a}$ & $62.20 \pm 8.03^{a}$ & $3.88 \pm 0.23^{a}$ \\
\hline & 1.5 & 1.5 & $0.062 \pm 0.01^{\mathrm{a}}$ & $32.34 \pm 12.48^{a}$ & $357.80 \pm 39.38^{b}$ & $62.10 \pm 16.61^{a}$ & $3.63 \pm 0.59^{a}$ \\
\hline & 2 & 1.5 & $0.066 \pm 0.01^{a}$ & $35.45 \pm 13.92^{\mathrm{a}}$ & $341.89 \pm 69.43^{b}$ & $70.46 \pm 21.73^{a}$ & $3.65 \pm 0.46^{a}$ \\
\hline
\end{tabular}

${ }^{\mathrm{a}-\mathrm{d}}$ Similar letters show that there is no statistical difference between different levels in the same column within each group at $P>0.05$.

fs, film-forming solution. 
concentrations of NA caused a disruption in film matrix resulting in changes in strength properties of the film. A slight increase in EM of NA-containing MC films was observed at low NA concentration. \% EB values of MC films were also affected by NA incorporation, and a slight decrease was observed. Addition of low concentration of NA in combination with RE did not result in any significant changes in TS of MC films. These changes might be because of the weakening of some of the chemical bonds in the polymer structure.

\section{Water vapour barrier properties of films}

WVP of the control and active agent containing WG and MC films are provided in Table 1. WVP of WG and MC control films were 6.85 and $3.50 \mathrm{~g} \mathrm{~mm} \mathrm{~m}^{-2} \mathrm{kPa}^{-1}$ $\mathrm{h}^{-1}$, respectively. Although Gontard et al. (1993) reported lower WVP values for WG films, results of our study were similar to Pommet et al.'s (2003) study. The differences could be attributed to film formulations as parameters such as protein concentration and plas- ticiser amounts could alter WVP values. Differences in WVP measuring conditions also cause differences in WVP values. WVP of MC film was in the range (3.02$4.36 \mathrm{~g} \mathrm{~mm} \mathrm{~m}^{-2} \mathrm{kPa} \mathrm{h}$ ) of what was reported by Park et al. (1993). There was no significant difference between WVP of control films and films containing active agents. Therefore, NA and NA + RE incorporation into WG and $\mathrm{MC}$ biopolymers did not have any effect on water vapour barrier properties of these films. Active agents did not probably cause any significant structural changes or plasticising effect in the films that would result in an increase in free volume. As will be explained in the section on infrared spectroscopy there were also no significant interactions between active agents and films. Therefore, WVP values also did not change with addition of active agents.

\section{Mid-infrared spectroscopy}

Infrared spectra of control films and films containing antifungal agents at various concentrations were
Figure 1 Fourier transform infra red spectra of wheat gluten films containing: (a) natamycin and (b) natamycin + rosemary extract.
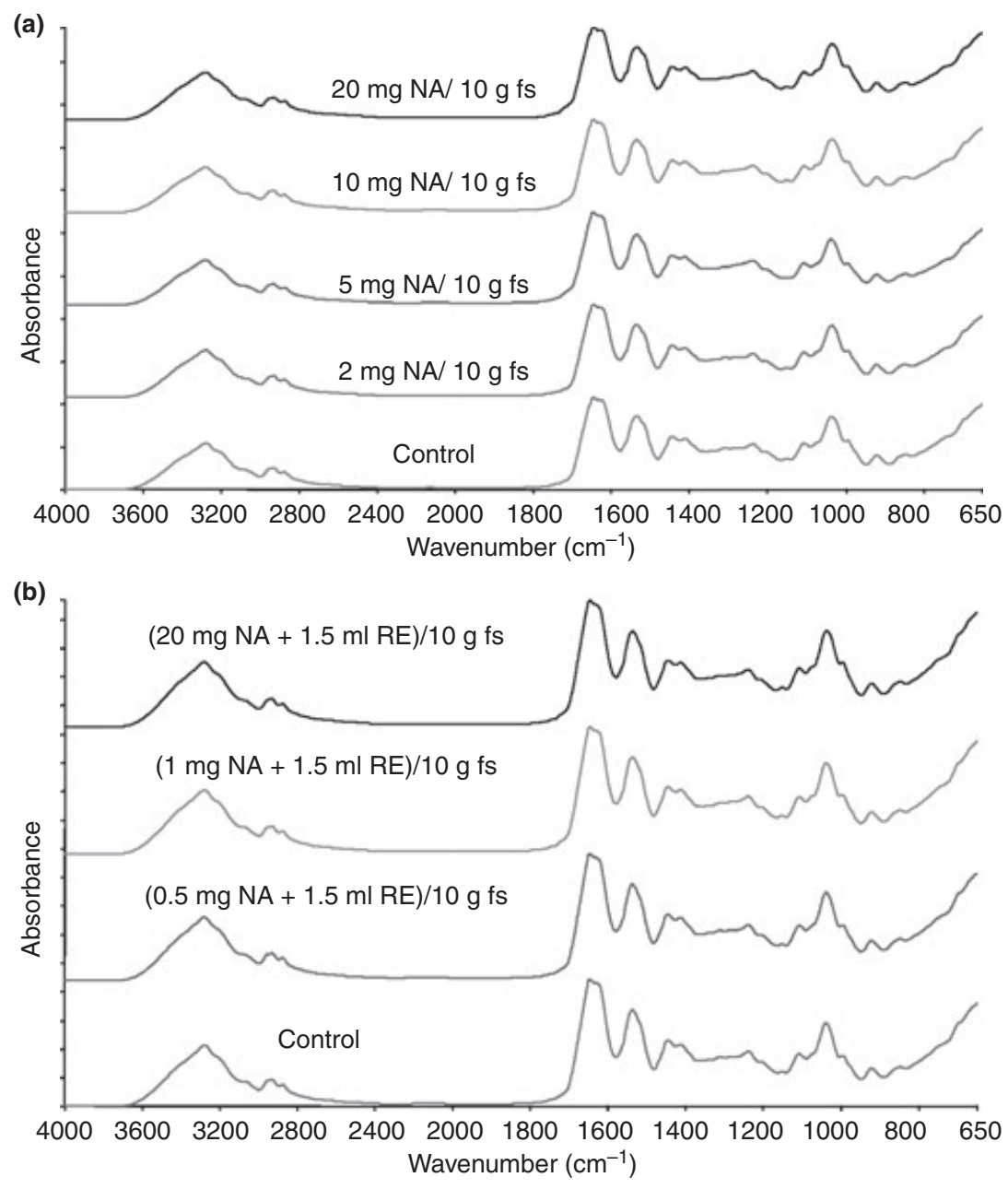
recorded to study the interaction between added agents and the biopolymers (Figs 1 and 2). Absorption bands corresponding to $\mathrm{N}-\mathrm{H}$ stretch at $3280 \mathrm{~cm}^{-1},-\mathrm{CH},-\mathrm{CH}_{2}$ and $-\mathrm{CH}_{3}$ stretching at $2935-2877 \mathrm{~cm}^{-1}$, amide carbonyl group at $1650 \mathrm{~cm}^{-1},-\mathrm{CH}_{2}$ and $-\mathrm{CH}_{3}$ groups at $1445-1415 \mathrm{~cm}^{-1}$ and $\mathrm{C}-\mathrm{N}$ stretch at $1039 \mathrm{~cm}^{-1}$ were observed for WG films. MC films had absorbance bands at $3400 \mathrm{~cm}^{-1}$ (O-H stretching), 2835-2940 $\mathrm{cm}^{-1}$ (C-H stretching), $1645 \mathrm{~cm}^{-1}$ (C-O), $1450-1315 \mathrm{~cm}^{-1}\left(-\mathrm{CH}_{2}\right.$ and $-\mathrm{CH}_{3}$ groups) and $1100-1000 \mathrm{~cm}^{-1}(\mathrm{C}-\mathrm{O}-\mathrm{C})$ which are similar to that were reported in literature (Zaccaron et al., 2005). All spectra belonging to control films and films containing NA and NA + RE have similar infra red absorbance patterns and formation of any new peaks or shifts in the peaks were not observed. Therefore, it could be concluded that there was no interaction between added agents and the WG and MC films. Pranoto et al. (2005) also did not observe any interaction between incorporated antimicrobial agents (garlic oil, potassium sorbate and nisin) and biopolymer, chitosan.

\section{Scanning electron microscopy}

SEM pictures of cross-sections of control films and films containing antifungal agents were also obtained to visually examine the structure of the films. Structure of WG control film was homogeneous as reported by Pochat-Bohatier et al. (2006; Fig. 3a). There was no visual change in the structure of $2 \mathrm{mg}$ NA per $10 \mathrm{~g}$ fs containing WG film (not shown). However, continuity of the film was disturbed at high NA concentrations and
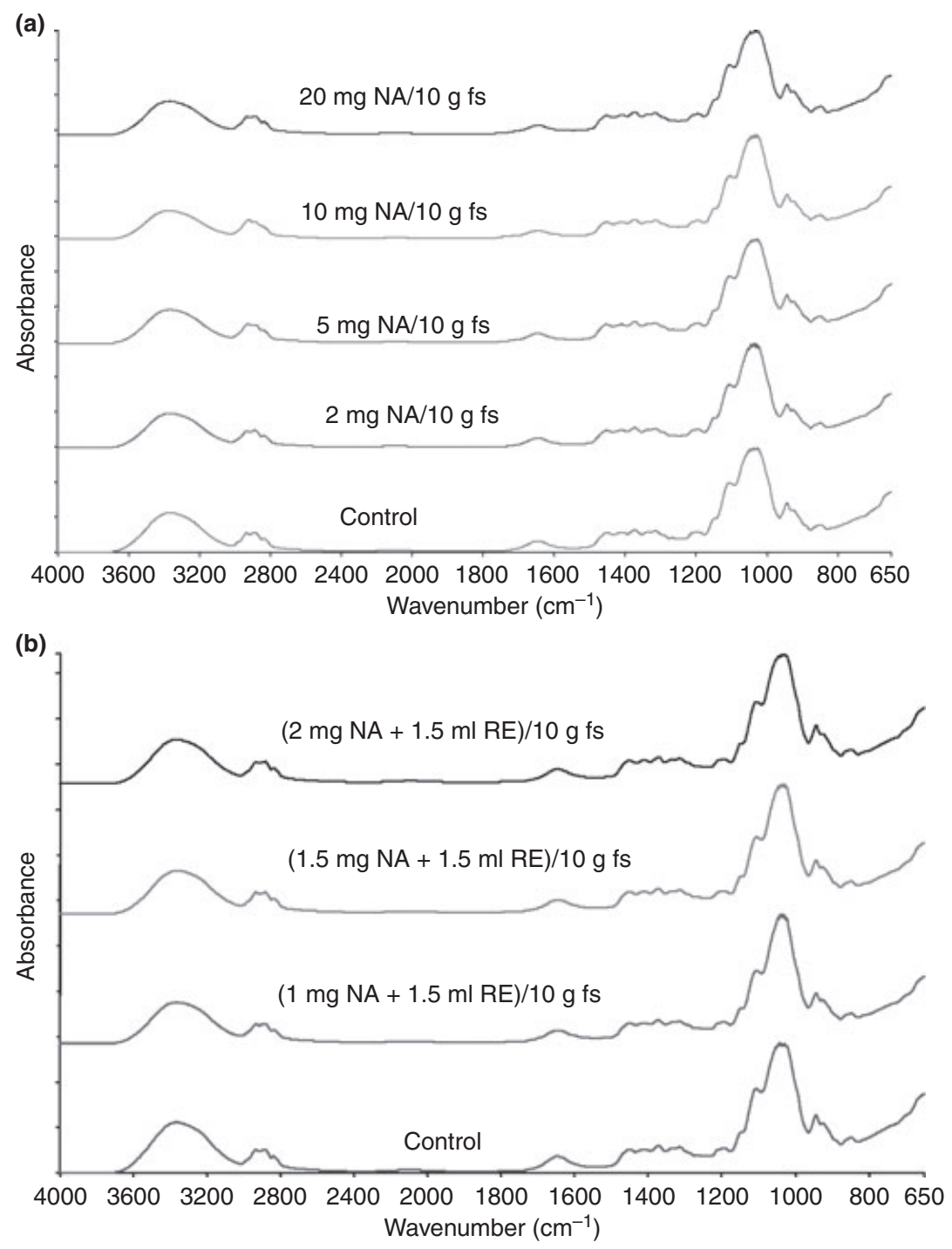

Figure 2 Fourier transform infra red spectra of methyl cellulose films containing: (a) natamycin and (b) natamycin + rosemary extract. 
Figure 3 Standard electron microscopic pictures of wheat gluten films: (a) control; (b) $20 \mathrm{mg}$ natamycin/ $10 \mathrm{~g}$ fs and (c) (2 mg natamycin $+1.5 \mathrm{~mL}$ rosemary extract) $/ 10 \mathrm{~g}$ fs (fs, film-forming solution).
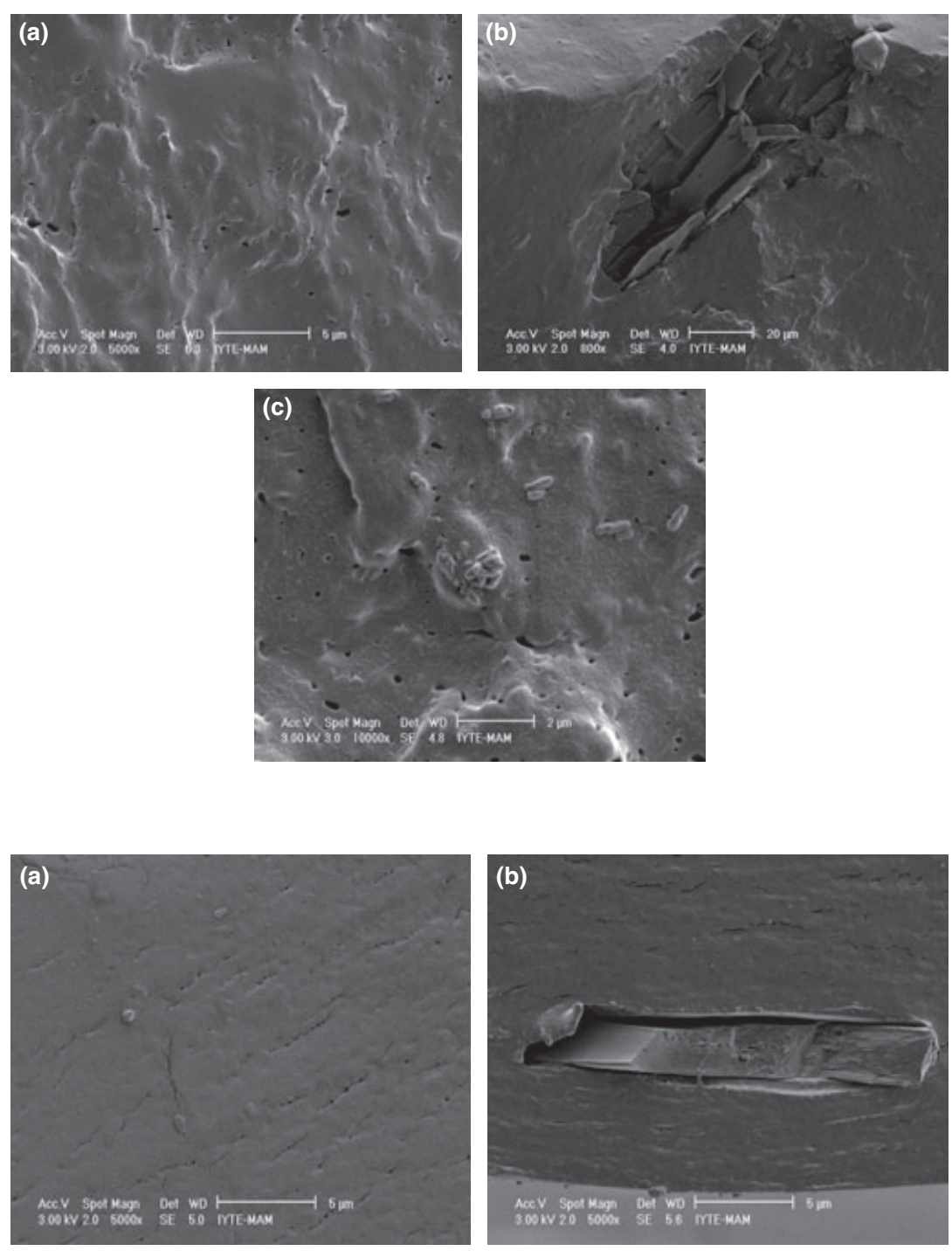

(c)
Figure 4 Standard electron microscopic pictures of methyl cellulose films: (a) control; (b) $20 \mathrm{mg}$ natamycin/10 $\mathrm{g}$ fs and (c) (2 mg natamycin $+1.5 \mathrm{~mL}$ rosemary extract) $/ 10 \mathrm{~g}$ fs (fs, film-forming solution).

holes were formed (Fig. 3b). In addition, NA crystalline structures were observed in the films. It was reported that NA suspension at $\mathrm{pH} 6.5$ has a stable crystalline form (Stark, 2003). With the addition of RE (1.5 mL per $10 \mathrm{~g} \mathrm{fs}$ ), besides NA, into WG films, small rod-shaped particles were observed in the film (Fig. 3c). These rod- shaped particles are probably RE as films containing only RE had these particles.

MC control films also had a homogeneous structure (Fig. 4a). $2 \mathrm{mg}$ NA per $10 \mathrm{~g}$ fs did not cause any change in the structure of the MC film. However, at high NA concentrations irregularities in the film structure were 
seen. As it was observed in WG films, there were crystalline structures in the film at $20 \mathrm{mg}$ NA per $10 \mathrm{~g}$ fs (Fig. 4b). Small particles as well as cracks occurred when RE (1.5 mL per $10 \mathrm{~g}$ fs) was incorporated into MC films in combination with NA (Fig. 4c).

From SEM observations, it could be concluded that NA homogeneously distributed in WG and MC films at low concentrations while it formed crystals at higher levels.

\section{Conclusions}

As a conclusion, high NA concentration in biopolymers resulted in discontinuity of the film structure. However, barrier properties were not affected from antimicrobial agent addition. Some changes were observed in mechanical properties depending on the antimicrobial concentration and film type.

\section{Acknowledgment}

This study was financially supported by the Scientific and Technological Research Council of Turkey (TUBITAK Project No.: 104O543). SEM analysis was performed in Izmir Institute of Technology Centre for Materials Research.

\section{References}

ASTM. (1996). Standard test methods for tensile properties of thin plastic sheeting, D882-91. Annual Book of ASTM. Philadelphia, PA: American Society for Testing and Materials.

Bifani, V., Ramírez, C., Ihl, M., Rubilar, M., García, A. \& Zaritzky, N. (2007). Effects of murta (Ugni molinae Turcz) extract on gas and water vapor permeability of carboxymethylcellulose-based edible films. Lebensmittel-Wissenschaft und-Technologie, 40, 14731481.

Cutter, C.N., Willett, J.L. \& Siragusa, G.R. (2001). Improved antimicrobial activity of nisin-incorporated polymer films by formulation change and addition of food grade chelator. Letters in Applied Microbiology, 33, 325-328.

Cuvelier, M.E., Berset, C. \& Richard, R. (1996). Antioxidative activity and phenolic composition of pilot-plant and commercial extracts of sage and rosemary. Journal of the American Oil Chemists' Society, 73, 645-652.

Gontard, N., Guilbert, S. \& Cuq, J.L. (1993). Water and glycerol as plasticizers affect mechanical and water vapor barrier properties of an edible wheat gluten film. Journal of Food Science, 58, 206-211.

Ko, S., Janes, M.E., Hettiarachchy, N.S. \& Johnson, M.G. (2001). Physical and chemical properties of edible films containing nisin and their action against Listeria monocytogenes. Journal of Food Science, 66, 1006-1011.

Madsen, H.L., Sorensen, B., Skibsted, L.H. \& Bertelsen, G. (1998). The antioxidant activity of summer savory (Satureja hortensis L.) and rosemary (Rosmarinus officinalis L.) in dressing stored exposed to light or in darkness. Food Chemistry, 63, 173-180.

Maizura, M., Fazilah, A., Norziah, M.H. \& Karim, A.A. (2007). Antibacterial activity and mechanical properties of partially hydrolyzed sago starch-alginate edible film containing lemongrass oil. Journal of Food Science, 72, C324-C330.

McHugh, T.H., Avena-Bustillos, R. \& Krochta, J.M. (1993). Hydrophilic edible films: modified procedure for water vapor permeability and explanation of thickness effects. Journal of Food Science, 58, 899-903.

Min, L.J., Harris, J. \& Krochta, M. (2005). Antimicrobial effects of lactoferrin, lysozyme, and the lactoperoxidase system and edible whey protein films incorporating the lactoperoxidase system against Salmonella enterica and Escherichia coli O157:H7. Journal of Food Science, 70, M332-M338.

de Oliveira, T.M., Soares, N.F.F., Pereira, R.M. \& Fraga, K.F. (2007). Development and evaluation of antimicrobial natamycin-incorporated film in gorgonzola cheese preservation. Food Packaging and Technology, 20, 147-153.

Ozdemir, M. \& Floros, J.D. (2003). Film composition effects on diffusion of potassium sorbate through whey protein films. Journal of Food Science, 68, 511-516.

Park, H.J., Weller, C.L., Vergano, P.J. \& Testin, R.F. (1993). Permeability and mechanical properties of cellulose-based edible films. Journal of Food Science, 58, 1361-1365.

Pochat-Bohatier, C., Sanchez, J. \& Gontard, N. (2006). Influence of relative humidity on carbon dioxide sorption in wheat gluten films. Journal of Food Engineering, 77, 983-991.

Pommet, M., Redl, A., Morel, M.H. \& Guilbert, S. (2003). Study of wheat gluten plasticization with fatty acids. Polymer, 44, 115-122.

Pranoto, Y., Rakshit, S.K. \& Salokhe, V.M. (2005). Enhancing antimicrobial activity of chitosan films by incorporating garlic oil, potassium sorbate and nisin. Lebensmittel-Wissenschaft und -Technologie, 38, 859-865.

Quattara, B., Simard, R.E., Piette, G., Bégin, A. \& Holley, R.A. (2000). Diffusion of acetic and propionic acids from chitosan-based antimicrobial packaging films. Journal of Food Science, 65, 768-773.

Schwarz, K. \& Ternes, W. (1992). Antioxidative constituents of Rosmarinus officinalis and Salvia officinalis. I. Determination of phenolic diterpenes with antioxidative activity amongst tocochromanols using HPLC. Zeitschrift Lebensmittel-Untersuchung und Forschchung, 195, 95-98.

Stark, J. (2003). Natamycin: an effective fungicide for food and beverages. In: Natural Antimicrobials for the Minimal Processing of Foods (edited by S. Roller). Pp. 82-97. Cambridge, GBR: Woodhead Publishing.

Ture, H., Eroglu, E., Soyer, F. \& Ozen, B. (2007). Testing the Antimicrobial Properties of Edible Films Incorporated with Natamycin and Rosemary Extract. 2nd Safoodnet Seminar, 22-23 October, Istanbul.

Turhan, K.N. \& Sahbaz, F. (2004). Water vapor permeability, tensile properties and solubility of methylcellulose-based edible films. Journal of Food Engineering, 61, 459-466.

Yildirim, M., Gulec, F., Bayram, M. \& Yildirim, Z. (2006). Properties of kashar cheese coated with casein as a carrier of natamycin. Italian Journal of Food Science, 18, 127-138.

Zaccaron, C., Oliveira, R., Guiotoku, M., Pires, A. \& Soldi, V. (2005). Blends of hydroxypropyl methylcellulose and poly(1-vinylpyrrolidoneco-vinyl acetate): miscibility and thermal stability. Polymer Degradation and Stability, 90, 21-27. 